Last revision: December 2001

\title{
Ex Ante Investments and Ex Post Externalities
}

\author{
Lucian Arye Bebchuk*
}

\begin{abstract}
$\underline{\text { Abstract }}$
Whenever the use of an asset by one party imposes an externality on another party's use of an asset, entitlements must be allocated. Does an upstream firm have a right to use a river's water or does a downstream firm have a right not to have the water used? And if the downstream firm is to be protected, should the protection come in the form of a property right or a liability rule? This paper focuses on how the allocation of entitlements affects ex ante investments and actions. Even when ex post bargaining is easy, the ex post allocation of entitlements, by affecting the distribution of ex post value, can have significant efficiency effects $e x$ ante. By identifying the ex ante effects of alternative rules, the analysis provides a framework for determining allocations of entitlement that would perform best from the perspective of ex ante efficiency. As far as ex ante effects are concerned, liability rules are not generally superior to property rights. The analysis has implications for a broad range of legal and policy questions.
\end{abstract}

JEL classification: D62, K10, K11.

Key words: externalities, property rights, liability rules, ex ante investments, regulation.

(C)2001 Lucian Bebchuk. All rights reserved.

* William J. Friedman Professor of Law, Economics, and Finance, Harvard Law School; Research Associate, National Bureau of Economic Research and Center for Economic Policy Research. A companion paper, "Property Rights and Liability Rules: The Ex Ante View of the Cathedral," provides an informal account of the results established in this paper. I am grateful to Oren Bar-Gill for his extremely valuable assistance. I have also benefited from the helpful comments and suggestions of Omri BenShahar, Bob Ellickson, Jesse Fried, Assaf Hamdani, Oliver Hart, Louis Kaplow, Eric Rasmusen, Suzanne Scotchmer, Steve Shavell, and participants in seminars at Berkeley, the Erasmus Program in Hamburg, Harvard, and Michigan. Finally, I wish to thank the John M. Olin Center for Law, Economics, and Business for its financial support and the University of Tel-Aviv for its hospitality during my visits. Future revisions of this paper may be retrieved from www.law.harvard.edu/faculty/bebchuk. 


\section{INTRODUCTION}

Because the use of assets might often impose an externality on the use of other assets, the law must define the boundaries of property rights. When an activity of an upstream factory would pollute a river's water in a way that would hurt an activity conducted by a downstream resort, for example, legal rights must be determined. Does the upstream factory have the right to engage in this activity or does the downstream resort have the right to water unpolluted by the upstream factory? And if the resort has the entitlement to unpolluted water, should the resort be protected by a property right (entitling the resort to get an injunction forcing the factory not to pollute) or by a liability rule (entitling the resort to damages in the event that the factory pollutes)? These are the type of questions that public policy and the law must resolve in the numerous instances in which uses of assets conflict.

Since the classic paper by Coase (1960), a significant law and economics literature has considered the allocation of entitlements in such cases. This literature has taken primarily an ex post view, by which I mean that it commonly took as given the payoffs that the parties would have with and without the actions that would impose an externality. Taking as given the presence of the factory and the resort in the considered example and their potential payoffs from operating, the commonly analyzed question concerns which allocation of entitlements would result in the factory polluting the river's water at the efficient level (if any). Given that bargaining is subject to transaction costs and imperfect information, such ex post efficiency cannot be guaranteed. The question thus arises which allocation of entitlements would best facilitate such bargaining and/or, if bargaining fails, would most likely produce an efficient outcome.

This paper focuses on the ex ante effects of allocations of entitlements when the structure of the ex post situation is influenced by ex ante investments by both parties. By ex ante 
decisions I label throughout those decisions that (i) are made by parties before the decisions whether to take the externality-producing actions are made, and (ii) influence the potential payoffs that the parties would obtain in the event that those actions took place. Such ex ante effects are, of course, ubiquitous. In the factory and resort example, the ex post payoffs situation might be influenced by the ex ante decisions of the factory and the resort whether to locate along the river (and, if so, how close to the river); what scope of activities to develop; what products or services to provide; how many workers to hire and how much to invest in their human capital; etc.

As in the incomplete contracting literature, the focus of my analysis will be on ex ante investments that are not verifiable by courts. As will be shown, in the presence of such investments, no ex post allocation of entitlements can generally guarantee optimal ex ante investments. Still, some allocations would do better than others. From the perspective of ex ante efficiency, the optimal allocation would be the one that overall would do best in terms of its ex ante effects. If the parties can bargain ex ante (say, grant an easement in the case of neighboring plots of land), this allocation will be the one that they will likely adopt. As will be discussed in detail later on, however, ex ante bargaining might sometimes be costly or difficult, even in cases in which ex post bargaining is easy. In such cases, it might be desirable to have this allocation provided as the default arrangement by the law.

In analyzing the ex ante decision of ex post allocations of entitlements, it is useful to distinguish between two cases - one in which ex post bargaining is easy and one in which it is not. I plan to analyze the latter case in subsequent work. My analysis here will focus on the case in which ex post bargaining is easy. In the standard ex post analysis, in cases where bargaining between the parties is easy ex post, the allocation of entitlements is irrelevant from the perspective of efficiency. As long as parties can bargain around legal rules, the efficient outcome would ensue. As the analysis below will show, however, even when bargaining is 
easy ex post, as it might be in the factory-resort case, alternative allocations of ex post entitlements might differ considerably in their efficiency consequences because of their effects on ex ante decisions.

To see the range of ex ante effects to be analyzed, consider first how the allocation of entitlements will affect the incentives of the factory in our example to invest ex ante in enhancing the value of the factory. When the resort has a property right to be free from pollution, the ex ante investment by the factory will be too low, because the resort's property right will enable the resort to capture part of the value created by the factory's ex ante investment. In contrast, if the factory enjoyed a property right to pollute, it would not have to share the value of its ex ante investment with the resort, and granting a property right to the factory will thus encourage it to invest ex ante. Indeed, for reasons to be identified, such a property right to pollute will lead the factory to invest excessively. Finally, if the resort has an entitlement protected by a liability rule, and must therefore be compensated by the factory for court-assessed damages from pollution, the factory will capture the full value from marginal increases in the value of the factory and the factory's investment in enhancing the value of its activities will be consequently efficient.

Consider now the effect of the allocation of entitlements on the incentives of the resort to invest in enhancing the value of its operations. Following a similar reasoning, granting a property right to the factory would enable it to extract some of the value created by the investment of the resort, thus leading to a sub-optimal investment by the resort. In contrast, if the resort has a property right, it would not be discouraged to invest in enhancing the value of its operations. Indeed, for reasons to become clear later, the resort might even invest excessively if granted a property right. Finally, granting the resort an entitlement to be free of pollution protected by a liability rule would not eliminate this excessive investment problem. 
Indeed, as will be shown, a liability rule protection would lead to the resort's investment being even more excessive than under a property right protection to the resort.

In addition to investments that affect the value of their respective operations, the parties might also make ex ante investments that affect the magnitude of the harm to the resort that might arise from the conflicting use of the river's water. The analysis shows that, if the resort is protected with a liability rule, the resort will have no incentive to make any such investments in harm-reduction, whereas the factory would have an incentive to make such investments at the socially optimal level. In contrast, if the rule takes the form of a property right, with either the factory or the resort having the property right, then both parties will have incentives to make some - but less than socially optimal - investments in reduction of potential harm from conflicting use.

There is thus a range of ex ante effects that the allocation of ex post entitlements might have, and the optimal rule, from an ex ante perspective, depends on the balance of these considerations. The paper's analysis provides a framework for determining this optimal rule by identifying the various ex ante effects associated with each allocation of entitlements. In particular, this framework enables us to identify the factors that are relevant for (i) choosing which party should get the entitlement, and (ii) choosing the form of protection that a given party should get. As to choice (ii), it is shown that, from an ex ante perspective, liability rules are not generally superior to property rights. This result is worth noting in light of the ex post advantages of liability rules that the literature has identified and analyzed.

The paper is related to two bodies of literature - the literature on literature on the design of property rights and liability rules and the literature on the ex ante effects of hold-up problems. The economic analysis of property rights and liability began with the seminal 
article of Calabresi and Melamed (1972), ${ }^{1}$ and the subject has been since extensively studied (e.g., Ayres and Talley (1995), Kaplow and Shavell (1996), and the articles in the Yale Law Journal 1997 symposium on property rights and liability rules). ${ }^{2}$ As already noted, the primary focus of this literature has been on identifying which rules would best attain ex post efficiency. ${ }^{3}$ In contrast, the focus of this paper is on how the design of property rights and liability rules affects ex ante investments in situations in which both sides' investments matter.

The second relevant literature is that on ex post hold-up problems and their ex ante consequences. ${ }^{4}$ The large literature on the subject has investigated how ex post hold-up problems shape the boundaries of firms and the design of contracting practices. ${ }^{5}$ This paper uses the analytical insights of this literature to shed light on a different context from those examined by this literature. Whereas this literature has focused on hold-out problems among parties that engage in some transaction or provision of product or service, this paper focuses

\footnotetext{
${ }^{1}$ Calabresi and Melamed investigated the choice between harmful externalities both in connection with harmful externalities and in connection with the protection of ownership in "things." Kaplow and Shavell (1996) show that the two contexts are rather different and call for separate treatment. The analysis of this paper is limited to the context of harmful externalities. Bebchuk (2001) develops an analysis, form an ex ante perspective, of the protection-of-ownership question.

${ }^{2}$ Other contributions to the literature include Polinsky (1979, 1980a, 1980b), Merril (1985), Krier and Schwab (1995), Ayres and Talley (1995), and the articles in the 1997 Yale Law Journal Symposium on Property Rules, Liability Rules, and Inalienability, Ayres and Goldblat (2001), and Avraham (2001).

${ }^{3}$ Some of the researchers whose analysis focused on what I term ex post effects have recognized the presence of what I term ex ante effects. In particular, Kaplow and Shavell (1996, 738-39) discuss how providing any protection to victims might discourage them from making investments that would reduce the potential harm to them from externality-producing actions. They explain that such a factor might influence the choice of rule, but they do not attempt to reach conclusions as to the conditions under which, in the presence of such investments, any given rule would be optimal. Ayres and Taley (1995) focus on the beneficial effect that liability rules have on ex post bargaining, but they also discuss (1083-1090) how ex ante considerations might militate against the use of liability rules.

${ }^{4}$ Klein, Crawford and Alchian (1978), Williamson (1975, 1979), and Grossman and Hart (1986) are pioneering contributors. More recent Contributions include Hart and Moore (1988), Chung (1991), Rogerson (1992), Macleod and Malcomson (1993), Aghion, Dewatripont and Rey (1994), Hart (1995), Noldeke and Schmidt (1995), Aghion and Tirole (1997).
} 
on parties that do not provide each other with any services or products (though they might be trading with others) and whose only connection to each other is the external cost that one party's activity might impose on the other. ${ }^{6}$

The remainder of the paper is organized as follows. Section II sets forth the framework of the analysis. Section III analyzes the ex post division of value produced by different legal rules. Section IV studies the effects of alternative rules on the parties' ex ante investments in enhancing the value of their activities and/or in reducing the harm caused to one of them by the other's activities. Section V analyzes how government fines might in theory improve ex ante investments. Section VI concludes. I have relegated proofs to the Appendix.

\section{FRAMEWORK OF ANALYSIS}

\section{A. Setting}

The model focuses on two economic actors (individuals or firms), F and R. For concreteness, suppose that up the river there is a factory $\mathrm{F}$ and down the river there is a resort R. F might benefit from engaging in a certain activity that would affect the water in a certain way that might harm R; we shall refer to this use of the water by F as "polluting" the water. The benefit that $\mathrm{F}$ will get from the activity polluting the water will be denoted by $V_{F}$. Thus, if $\mathrm{F}$ were not to pollute, $\mathrm{F}$ would lose $V_{F}$. It will not matter for the analysis whether the considered activity is the only one that $\mathrm{F}$ would be engaged in. Having the water of the river

\footnotetext{
${ }^{5}$ See, e.g., Grossman and Hart (1986), Hart and Moore (1990), Rajan and Zingales (1998). In the law and economics literature, the insights of the hold up literature have been applied to the design of contractual remedies. See Rogerson (1984) and Edlin and Reichelstein (1996).

${ }^{6}$ One of paper in this literature, Pitchford and Snyder (1999), analyzes the ex ante consequences of the allocation of entitlements. They develop a model in which parties arrive sequentially to a neighborhood, and they analyze how the parties' ex ante decisions whether to locate there will be affected by the rules that would govern ex post externalities.
} 
unpolluted in the considered way is helpful to an activity of the resort R; again, it will not matter whether $\mathrm{R}$ has other activities. This activity will produce a value of $V_{R}$ if the water is unpolluted and a value of $V_{R}-H$ if the water is polluted. Note that, since $\mathrm{R}$ can always shut down the considered activity, R could always limit the damage to $V_{R}$ if $H$ happens to exceed it. Thus, the damage from water pollution to $\mathrm{R}$ is $\min \left(V_{R}, H\right)$. As specified below, $V_{F}, V_{R}$ and $H$ are stochastic functions of the players ex ante actions.

\section{B. Sequence of Events}

The sequence of events in the model, which is illustrated in Figure 1 below, is as follows: $\mathrm{T}=1$ : The players take various actions that affect the values of $V_{F}, V_{R}$ and $H$.

$\mathrm{T}=2$ : Uncertainty, which affects the stochastic variables $V_{F}, V_{R}$ and $H$, is resolved. The realization of the state of nature at $\mathrm{T}=2$, together with the ex ante actions chosen at $\mathrm{T}=1$, determine the ex post values of $V_{F}, V_{R}$ and $H$.

$\mathrm{T}=3$ : Given the legal rule, the players might renegotiate their rights.

$\mathrm{T}=4$ : The players engage in, or refrain from engaging in, their activities.

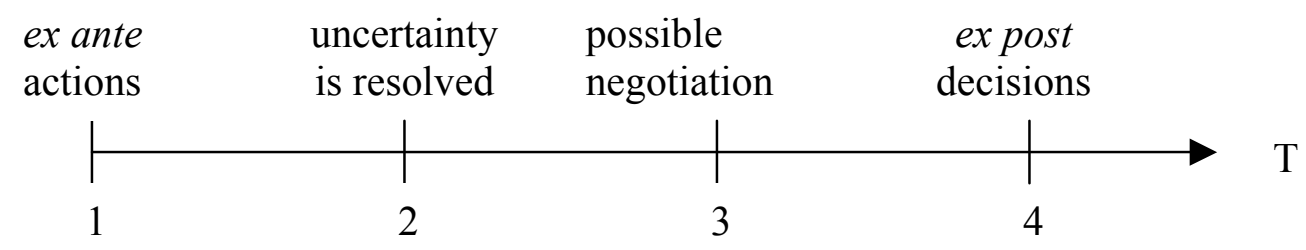

We shall now turn to specify the assumptions regarding each of the four stages. 


\section{C. $T=1:$ Ex ante Actions}

The stochastic variables $V_{F}, V_{R}$ and $H$ are functions of the state of nature but also of $e x$ ante actions taken by the two players. Specifically, I assume that the expected value of $V_{F}$, $V_{R}$ and $H$ are $\bar{V}_{F}\left(x_{F}\right), \bar{V}_{R}\left(x_{R}\right)$ and $\bar{H}\left(y_{F}, y_{R}\right)$, where $x_{F}$ and $x_{R}$ represent investments that $\mathrm{F}$ and $\mathrm{R}$ may make respectively to enhance the value of their respective activities, and $y_{F}$ and $y_{R}$ represent investments in harm reduction that may be taken by $\mathrm{F}$ and $\mathrm{R}$ respectively.

I adopt the standard assumptions of diminishing returns to investments in enhancing $V_{F}$ and $V_{R}$ and in reducing $H$, i.e. $\bar{V}_{F}^{\prime}\left(x_{F}\right)>0, \bar{V}_{F}^{\prime \prime}\left(x_{F}\right)<0, \bar{V}_{R}^{\prime}\left(x_{R}\right)>0, \bar{V}_{R}^{\prime \prime}\left(x_{R}\right)<0$, $\bar{H}_{y_{F}}^{\prime}\left(y_{F}, y_{R}\right)<0, \bar{H}_{y_{F}}^{\prime \prime}\left(y_{F}, y_{R}\right)>0, \bar{H}_{y_{R}}^{\prime}\left(y_{F}, y_{R}\right)<0, \bar{H}_{y_{R}}^{\prime \prime}\left(y_{F}, y_{R}\right)>0 .^{7}$

I assume that the ex ante investments $\left(x_{F}, x_{R}, y_{F}\right.$ and $\left.y_{R}\right)$ are non-contractible. Noncontractibility might arise from the non-verifiability of the ex ante actions in a court of law. Thus, given the nonverifiability of ex ante investments, no contractual or legal arrangement can be based on specifying their levels.

As will be shown, given that ex ante investments cannot be verified, no arrangement concerning the allocation of the parties' ex post entitlements will induce optimal ex ante levels for all of the parties' different investments. The question to be considered, however, is which arrangement will maximize ex ante expected total value.

If the parties could contract at $\mathrm{T}=1$, they would be able to adopt this best arrangement by contract. As long as bargaining at $\mathrm{T}=1$ is not costless, however, providing this arrangement by law as a default would be desirable. And to the extent that bargaining at $\mathrm{T}=1$ might fail, providing this arrangement by law as a default would further increase in importance.

\footnotetext{
${ }^{7}$ Also, in order to preclude corner solutions, I adopt the standard assumption that the first derivatives are sufficiently large (in absolute value) at zero.
} 
Note that bargaining at $\mathrm{T}=1$ might be difficult even in those cases where bargaining at $\mathrm{T}=3$ is easy. Impediments to bargaining present at $\mathrm{T}=1$ might be alleviated by the time $\mathrm{T}=3$. To start with, one of the parties might have to make investments before the other party is present or accessible. ${ }^{8}$ Moreover, while we assume that both sides know at $\mathrm{T}=3$ the realization of the value of the other side's activity and of the potential harm that will occur if both activities take place, there might be some private information at $\mathrm{T}=1$ at $\mathrm{T}=1$. For example, $\mathrm{F}$ might have some private information regarding the function $\bar{V}_{F}\left(x_{F}\right)$, and/or $\mathrm{R}$ might have at $\mathrm{T}=1$ some private information regarding the function $\bar{V}_{R}\left(x_{R}\right)$, and/or one of the parties (or both) might have private information about the effectiveness of this party's investments in reducing harm. Such informational asymmetries might be an impediment to bargaining over the legal rule at $\mathrm{T}=1$.

In any event, as long as bargaining at $\mathrm{T}=1$ is not costless, it would be worthwhile to identity the arrangement that would maximize expected total value. And this is the question on which the analysis will focus.

\section{D. $T=2$ : Resolution of Uncertainty}

The variables $V_{F}, V_{R}$ and $H$ are functions of the state of nature, which may be described by a triplet of random variables: $\left(\theta_{F}, \theta_{R}, \theta_{H}\right)$. All three random variables are assumed to have a positive support and a mean of 1 . Using this notation, $V_{F}, V_{R}$ and $H$ are defined as -

\footnotetext{
${ }^{8}$ To be sure, if $\mathrm{R}$ does not exist at $\mathrm{T}=1, \mathrm{~F}$ might try to negotiate with the owner of each one of the lots down the river which could fit a resort an agreement concerning externalities with respect to a resort should one be built on the owner's lot. (Suppose for simplicity that it would not make economic sense to have more than one resort in this area but that the resort could be built on different lots along the river.) Such bargaining will be impeded by the informational problems to be discussed presently and possibly also by a large-numbers problem.
} 


$$
\begin{aligned}
& V_{F} \equiv \theta_{F} \cdot \bar{V}_{F}\left(x_{F}\right) \\
& V_{R} \equiv \theta_{R} \cdot \bar{V}_{R}\left(x_{R}\right) \\
& H \equiv \theta_{H} \cdot \bar{H}\left(y_{F}, y_{R}\right)
\end{aligned}
$$

At $\mathrm{T}=2$ uncertainty is resolved, $\theta_{F}, \theta_{R}$, and $\theta_{H}$ are realized and the values of $V_{F}, V_{R}$ and $H$ become known.

\section{E. $T=3:$ Possible Negotiations}

In order to concentrate on the ex ante effects of different allocations of property rights, I shall assume below that, at $\mathrm{T}=3, V_{F}, V_{R}$ and $H$ are all common knowledge (to $\mathrm{F}$ and $\mathrm{R}$ ) and that bargaining is costless. (The results of the model could be adjusted to apply to cases in which bargaining incurs certain transaction costs.) Under these assumptions, the ex post efficient outcome will be always reached.

As will be discussed, although ex post efficiency is guaranteed, the $\mathrm{T}=3$ negotiation stage will affect the efficiency of ex ante actions through its effect on the division of value between $\mathrm{F}$ and $\mathrm{R}$. To specify the bargaining procedure, I use the conventional assumption that $\mathrm{R}$ will make a take-it-or-leave-it offer with probability $\phi \in[0,1]$, and that $\mathrm{F}$ will make a takeit-or-leave-it offer with probability $1-\phi$.

\section{F. $T=4:$ Activities and Realization of Values}

At this final stage of the game the two players decide whether or not to engage in their respective activities. If $\mathrm{F}$ operates, it creates a value $V_{F}$. If $\mathrm{R}$ operates, it creates a value $V_{R}$. Also, if both $\mathrm{F}$ and $\mathrm{R}$ operate, $\mathrm{F}$ inflicts a harm $H$ upon $\mathrm{R}$. Finally, payments from one party to the other may take place according to the initial entitlements and the $\mathrm{T}=3$ contract. 
In analyzing the ex post efficient outcome, three possible scenarios should be distinguished:

(1) Scenario FR: If $\min \left(V_{F}, V_{R}, H\right)=H$, then the efficient outcome is for both players to operate and thus for $\mathrm{R}$ to bear the harm $\mathrm{H}$.

(2) Scenario F: If $\min \left(V_{F}, V_{R}, H\right)=V_{R}$, then the efficient outcome is for only $\mathrm{F}$ to operate and for R to shut down. In this scenario, F should definitely operate since $V_{F}>V_{R}$ and, given that $\mathrm{F}$ is going to operate, it is efficient for $\mathrm{R}$ to shut down since $H>V_{R}$.

(3) Scenario R: If $\min \left(V_{F}, V_{R}, H\right)=V_{F}$, then the efficient outcome is for only $\mathrm{R}$ to operate and for $\mathrm{F}$ to shut down. In this scenario, if $\mathrm{R}$ operates $\mathrm{F}$ should shut down since $V_{F}<H$, and R should indeed operate since $V_{R}>V_{F}$.

Table 1: The Ex post Efficient Outcomes in the Three Scenarios

\begin{tabular}{|c|c|c|c|}
\hline Scenario & F's Activity & R's Activity & Total Value \\
\hline $\begin{array}{c}\text { Scenario FR } \\
\min \left(V_{F}, V_{R}, H\right)=H\end{array}$ & Yes & Yes & $V_{F}+V_{R}-H$ \\
\hline $\begin{array}{c}\text { Scenario F } \\
\min \left(V_{F}, V_{R}, H\right)=V_{R}\end{array}$ & Yes & No & $V_{F}$ \\
\hline $\begin{array}{c}\text { Scenario R } \\
\min \left(V_{F}, V_{R}, H\right)=V_{F}\end{array}$ & No & Yes & $V_{R}$ \\
\hline
\end{tabular}

Let $P^{F R}$ denote the probability of scenario FR (in which both F and R operate), let $P^{F}$ denote the probability of scenario $\mathrm{F}$ (in which only $\mathrm{F}$ operates), and let $P^{R}$ denote the probability of scenario $\mathrm{R}$ (in which only $\mathrm{R}$ operates). Hence $P^{F R}+P^{F}+P^{R}=1$. For simplicity I will assume that which scenario obtains is determined by the state of nature. The 
ex ante investments affect the values of a given activity within the scenario chosen by the state of nature, but not which activity if any should be shut down. (In the example of the factory and the resort, one could assume that which scenario obtains depends on the type of demand existing for the product or services offered by each of the firms.) Thus, $P^{F R}, P^{F}$ and $P^{R}$ will be treated in the analysis as constants and not functions of the ex ante investments. Finally, it will be assumed that each of the three scenarios is possible - that is, that $P^{F R}, P^{F}$ and $P^{R}$ are all positive - but I will remark from time to time on the results in the special case where one or two of them are equal to zero.

\section{The EX POSt Division of VALue}

\section{A. Alternative Legal Rules}

Following Calabresi and Melamed (1972), we will study four alternative legal rules: ${ }^{9}$

(1) Entitlement to R protected by a Property right (the RP rule): Under this rule, R has an entitlement to operate free of harm, and this entitlement is protected by a property right - the state will ensure that $\mathrm{F}$ does not disturb R's operation (i.e. that $\mathrm{F}$ does not operate) unless $\mathrm{R}$ agrees to tolerate the harm.

(2) Entitlement to R protected by a Liability rule (the RL rule): Under this rule, R has an entitlement to operate free of harm, and this entitlement is protected by a liability rule $-\mathrm{F}$ may disturb R's operation, but in such a case F will have to pay R its damages from R's operations which are equal to $\min \left(H, V_{R}\right)$.

9 Recent work has put forward additional alternative rules (see, e.g, Krier and Schwab (1995), Levmore (1997), Ayres and Goldblat (2001), Avraham (2001)) and analyzed the ex post consequences of such rules. The analysis to follow can be adjusted to analyze also the ex ante effects of these additional rules. 
(3) Entitlement to F protected by a Property right (the FP rule): Under this rule F has an entitlement to operate and this entitlement is protected by a property right - the state will give $\mathrm{F}$ freedom to operate, and $\mathrm{R}$ will have to bear the harm $\mathrm{H}$ unless $\mathrm{F}$ agrees to shut down.

(4) Entitlement to F protected by a Liability rule (the FL rule): Under this rule F has an entitlement to operate and harm $\mathrm{R}$, but this entitlement is protected by a liability rule $-\mathrm{R}$ can force $\mathrm{F}$ to shut down if $\mathrm{R}$ pays $\mathrm{F}$ its damages $V_{F}$ from shutting down. ${ }^{10}$

Note the different informational requirements imposed on the court by the four alternative rules. Under all rules except for FP, the court will have to know whether $\mathrm{F}$ is engaged in its activity, and I will assume that this can be indeed verified by the court. Under the RL rule and FL rule, the court will have to verify not only whether F is engaged in the activity but also the level of the damages to $\mathrm{R}-$ that is, the level of $\min \left(H, V_{R}\right)$. When analyzing the consequences of each of these two liability rules, I will assume for simplicity of exposition that the court will be able ex post to assess damages accurately. However, as will be clear, the results will generally apply also to the case in which the court will observe damages with an error.

\section{B. The Division of Value under Alternative Rules}

As specified earlier, there are three scenarios for the efficient outcome. The following three lemmas present the actual outcome and transfer payment, if any, that will obtain under the various rules in each of the three scenarios. The main point driving the results is that the

\footnotetext{
${ }^{10}$ Unlike the other three rules, the FL rule is not in use (for reasons that research has not yet adequately explored). Nevertheless, I will include this rule in the analysis for the sake of completeness.
} 
legal rule affects the players' reservation prices in the negotiation stage, and by so doing it influences the division of value between the two players. ${ }^{11}$

Lemma 1: If $\min \left(V_{F}, V_{R}, H\right)=H$, both $\mathrm{F}$ and $\mathrm{R}$ will operate and $\mathrm{R}$ will bear the harm under all four legal rules. In addition:

(i) Under the RP rule, $\mathrm{F}$ will pay $\mathrm{R}$ a sum of $H+\phi\left(V_{F}-H\right)$.

(ii) Under the RL rule, F will pay $\mathrm{R}$ a sum of $H$.

(iii) Under the FP rule, no payment will be made.

(iv) Under the FL rule, no payment will be made.

As a result, the division of value will be as indicated in Table 2 .

Table 2: The Division of Value under the Four Rules in Scenario FR

\begin{tabular}{|c|c|c|c|}
\hline Rule & Value to $\mathrm{F}$ & Value to R & Total Value \\
\hline $\mathrm{RP}$ & $\begin{array}{l}V_{F}-\left[H+\phi\left(V_{F}-H\right)\right]= \\
=(1-\phi)\left(V_{F}-H\right)\end{array}$ & $\begin{array}{l}V_{R}-H+\left[H+\phi\left(V_{F}-H\right)\right]= \\
=V_{R}+\phi\left(V_{F}-H\right)\end{array}$ & $V_{F}+V_{R}-H$ \\
\hline $\mathrm{RL}$ & $V_{F}-H$ & $V_{R}-H+H=V_{R}$ & $V_{F}+V_{R}-H$ \\
\hline $\mathrm{FP}$ & $V_{F}$ & $V_{R}-H$ & $V_{F}+V_{R}-H$ \\
\hline $\mathrm{FL}$ & $V_{F}$ & $V_{R}-H$ & $V_{F}+V_{R}-H$ \\
\hline
\end{tabular}

${ }^{11}$ In an interesting recent paper, Schankerman and Scotchmer (2001) analyze the effects of injunctions and damages (i.e., property rights and liability rules) on the division of value in disputes between patent-holders and second-stage inventors using (or infringing on) these patents. However, they do not seek to identify which ex post distribution would be optimal in terms if its ex ante effects, which is the focus of my analysis. 
Remarks: The intuition for this result, whose detailed proof is omitted, is as follows. In scenario FR, the efficient outcome is for both F and R to operate. Given that there are no impediments to bargaining, the efficient outcome will always be reached, and the legal rule will affect only the division of value.

(i) Under the RP rule, $\mathrm{R}$ has the right to prevent $\mathrm{F}$ from operating. Given that $V_{F}>H$, however, $\mathrm{R}$ will "sell" this right to $\mathrm{F}$, since the sale will produce a surplus of $V_{F}-H$. The expected value of the price that will be paid by $\mathrm{F}$ to $\mathrm{R}$ will equal $H$, the harm that $\mathrm{R}$ will bear, plus a fraction $\phi$ of the surplus $V_{F}-H$.

(ii) Under the RL rule, F can operate without R's consent but will be required in such a case to pay damages in the amount of $H$. Therefore, $\mathrm{R}$ will not be able to extract from $\mathrm{F}$ an amount exceeding $H$. On the other hand, since the legal rule guarantees a damage award of $H$, R will not agree to any payment below $H$.

(iii) Under the FP rule, F has the right to operate without paying damages. Since F's operation is efficient, there will be no incentive for the players to engage in bargaining for a reallocation of rights. Accordingly, $\mathrm{R}$ will be unable to extract any fraction of the surplus created by F's activity.

(iv) Under the FL rule, R has the right to stop F's activity provided that R pay F damages in the amount of $V_{F}$. Since $V_{F}>H$, however, R will prefer not to exercise this option.

Lemma 2: If $\min \left(V_{F}, V_{R}, H\right)=V_{R}$, only $\mathrm{F}$ will operate under all four legal rules, and

(i) Under the RP rule, F will pay $\mathrm{R}$ a sum of $V_{R}+\phi\left(V_{F}-V_{R}\right)$;

(ii) Under the RL rule, F will pay $\mathrm{R}$ a sum of $V_{R}$;

(iii) Under the FP rule, no payment will be made; and 
(iv) Under the FL rule, no payment will be made.

As a result, the division of value will be as indicated in Table 3.

Table 3: The Division of Value under the Four Rules in Scenario F

\begin{tabular}{|c|r|r|c|}
\hline Rule & Value to F & Value to R & Total Value \\
\hline \multirow{2}{*}{ RP } & $\begin{array}{l}V_{F}-\left[V_{R}+\phi\left(V_{F}-V_{R}\right.\right. \\
=(1-\phi)\left(V_{F}-V_{R}\right)\end{array}$ & $V_{R}+\phi\left(V_{F}-V_{R}\right)$ & $V_{F}$ \\
\hline RL & $V_{F}-V_{R}$ & $V_{R}$ & \\
\hline FP & $V_{F}$ & 0 & $V_{F}$ \\
\hline FL & $V_{F}$ & 0 & $V_{F}$ \\
\hline
\end{tabular}

Remarks: The intuition for this result, whose detailed proof is omitted, is as follows. Again, the assumption that negotiations at $\mathrm{T}=3$ are costless ensures that the efficient outcome of $\mathrm{F}$ operating and $\mathrm{R}$ shutting down will occur. The legal rules will affect only the division of value:

(i) Under the $\mathrm{RP}$ rule, $\mathrm{R}$ has the right to prevent $\mathrm{F}$ from operating. Given that $V_{F}>V_{R}$, however, R will "sell" this right to $\mathrm{F}$, since the transaction produces a surplus of $V_{F}-V_{R}$. The expected price that will be paid by $\mathrm{F}$ to $\mathrm{R}$ is $V_{R}$ plus a fraction $\phi$ of the surplus $V_{F}-V_{R}$.

(ii) Under the RL rule, F can operate without R's consent but will be required in such a case to pay damages $V_{R}$. R will not be able to extract from $\mathrm{F}$ an amount exceeding the 
expected damage award $V_{R}$. On the other hand, $\mathrm{R}$ will not agree to any offer of payment below the expected damage award.

(iii) Under the FP rule, F has the right to operate without paying damages. Since F's operation is efficient, there will be no incentive for the players to engage in bargaining for the reallocation of rights.

(iv) Under the FL rule, $\mathrm{R}$ can force $\mathrm{F}$ to shut down if $\mathrm{R}$ pays $\mathrm{F}$ a damage amount of $V_{F}$. However, since $V_{F}>V_{R}, \mathrm{R}$ will prefer not to interfere with F's operations and $\mathrm{R}$ will shut down herself.

Lemma 3: If $\min \left(V_{F}, V_{R}, H\right)=V_{F}$, only R will operate under all four legal rules, and

(i) Under the RP rule, no payment will be made;

(ii) Under the RL rule, no payment will be made;

(iii) Under the FP rule, $\mathrm{R}$ will pay $\mathrm{F}$ an amount of $V_{F}+(1-\phi)\left(\min \left(H, V_{R}\right)-V_{F}\right)$. Specifically, if $V_{R}>H, \mathrm{R}$ will pay $\mathrm{F}$ a sum of $V_{F}+(1-\phi)\left(H-V_{F}\right)$, and if $V_{R}<H, \mathrm{R}$ will pay $\mathrm{F}$ a sum of $V_{F}+(1-\phi)\left(V_{R}-V_{F}\right)$.

(iv) Under the FL rule, $\mathrm{R}$ will pay $\mathrm{F}$ a sum of $V_{F}$.

As a result, the division of value will be as indicated in Table 4 . 
Table 4: The Division of Value under the Four Rules in Scenario R

\begin{tabular}{|c|c|c|c|}
\hline Rule & Value to $\mathrm{F}$ & Value to $\mathrm{R}$ & $\begin{array}{l}\text { Total } \\
\text { Value }\end{array}$ \\
\hline $\mathrm{RP}$ & 0 & $V_{R}$ & $V_{R}$ \\
\hline $\mathrm{RL}$ & 0 & $V_{R}$ & $V_{R}$ \\
\hline FP & $\begin{array}{c}V_{F}+(1-\phi)\left(H-V_{F}\right)= \\
=H-\phi\left(H-V_{F}\right) \\
\text { if } V_{R}>H ; \text { and } \\
V_{F}+(1-\phi)\left(V_{R}-V_{F}\right)= \\
=V_{R}-\phi\left(V_{R}-V_{F}\right) \\
\text { if } V_{R}<H\end{array}$ & $\begin{array}{c}V_{R}-\left[V_{F}+(1-\phi)\left(H-V_{F}\right)\right]= \\
=V_{R}-H+\phi\left(H-V_{F}\right) \\
\text { if } V_{R}>H ; \text { and } \\
V_{R}-\left[V_{F}+(1-\phi)\left(V_{R}-V_{F}\right)\right]= \\
=\phi\left(V_{R}-V_{F}\right) \\
\text { if } V_{R}<H\end{array}$ & $V_{R}$ \\
\hline $\mathrm{FL}$ & $V_{F}$ & $V_{R}-V_{F}$ & $V_{R}$ \\
\hline
\end{tabular}

Remarks: The intuition for this result is as follows. The efficient outcome of $\mathrm{R}$ operating and F shutting down will again be always obtained, and the legal rules will affect only the division of value as follows:

(i) Under the RP rule, R has the right to operate without paying damages. Since R's operation is efficient, there will be no incentive for the players to engage in bargaining for the reallocation of rights.

(ii) Under the RL rule, $\mathrm{F}$ can operate at the cost of paying $\mathrm{R}$ damages in the amount of $H$ or $V_{R}$ (depending upon the relative magnitudes of $H$ and $V_{R}$ ). However, since $V_{F}<\min \left(H, V_{R}\right), \mathrm{F}$ will prefer to shut down and avoid the damage payment. 
(iii) Under the $\mathrm{FP}$ rule, $\mathrm{F}$ has the right to operate and harm $\mathrm{R}$, but given that $V_{F}<\min \left(H, V_{R}\right), \mathrm{F}$ will "sell" this right to $\mathrm{R}$, since the transaction produces a surplus of $\min \left(H, V_{R}\right)-V_{F}$. F's reservation price in the bargaining game is clearly $V_{F}$. R's reservation price depends upon the relative magnitude of $H$ and $V_{R}$. First, consider the case where $V_{R}>H$. In this case, $\mathrm{R}$ will operate regardless of F's operations, and if $\mathrm{F}$ agrees to shut down R gains $H$. Hence, R's reservation price is $H$, and the expected price that will be paid by $\mathrm{R}$ to F is $V_{F}$ plus a fraction $1-\phi$ of the surplus $H-V_{F}$. Now, consider the case where $V_{R}<H$. In this case, $\mathrm{R}$ will shut down if $\mathrm{F}$ operates, and thus if $\mathrm{F}$ agrees to shut down $\mathrm{R}$ will gain $V_{R}$. Hence, R's reservation price is $V_{R}$, and the expected price that will be paid by $\mathrm{R}$ to $\mathrm{F}$ is $V_{F}$ plus a fraction $1-\phi$ of the surplus $V_{R}-V_{F}$.

(iv) Under the FL rule, R can prevent F's operation by paying him a damage amount of $V_{F}$. Therefore, F will not be able to extract from $\mathrm{R}$ an amount exceeding $V_{F}$. On the other hand, since the legal rule guarantees a damage award of $V_{F}, \mathrm{~F}$ will not agree to any offer of payment below $V_{F}$.

\section{EX ANTE INVESTMENTS}

I now turn to examine how the different legal rules, through their effect on the ex post division of value, influence the players' ex ante investments. Sections A and B analyze the effects on parties' investments in enhancing the values of their activities, Section $\mathrm{C}$ then analyzes the effects on parties' investments in harm-reduction, and Section D finally turns to an overall comparison of the alternative rules in terms of their ex ante effects. 


\section{A. F's Ex ante Investment in Enhancing $V_{F}$}

\section{The Optimal Investment Level}

In setting $x_{F}$, the social objective is to maximize:

$$
P^{F R} \cdot E\left[V_{F}+V_{R}-H-x_{F}-x_{R}\right]+P^{F} \cdot E\left[V_{F}-x_{F}-x_{R}\right]+P^{R} \cdot E\left[V_{R}-x_{F}-x_{R}\right]
$$

or

$$
\left(P^{F R}+P^{F}\right) \cdot \bar{V}_{F}\left(x_{F}\right)+\left(P^{F R}+P^{R}\right) \cdot \bar{V}_{R}\left(x_{R}\right)-x_{F}-x_{R}-P^{F R} \cdot \bar{H}
$$

Thus, the optimal level of $x_{F}, x_{F}^{*}$, is the one that maximizes:

$$
\left(P^{F R}+P^{F}\right) \cdot \bar{V}_{F}\left(x_{F}\right)-x_{F}
$$

Based on these observations, we can state:

Lemma 4: The optimal level of $x_{F}, x_{F}^{*}$, is characterized by -

$$
\text { (1) }\left(P^{\mathrm{FR}}+P^{\mathrm{F}}\right) \cdot \bar{V}_{F}^{\prime}\left(x_{F}^{*}\right)=1
$$

Remark: The intuition for this lemma is that it is socially desirable to increase $x_{F}$ as long as the marginal utility from such an increase, $\left(P^{\mathrm{FR}}+P^{\mathrm{F}}\right) \cdot \bar{V}_{F}^{\prime}\left(x_{F}^{*}\right)$, is larger than the marginal cost of 1. The $\left(P^{\mathrm{FR}}+P^{\mathrm{F}}\right)$ multiplier in equation (1) reflects the fact that only in two out of the three possible scenarios F will actually operate (and optimally should operate).

\section{Investment Levels under the Four Alternative Rules}

\section{Proposition 1:}

(i) Under the RP rule, F's level of investment, $x_{F}^{R P}$, will be sub-optimal: $x_{F}^{R P}<x_{F}^{*}$;

(ii) Under the RL rule, F's level of investment, $x_{F}^{R L}$, will be optimal: $x_{F}^{R L}=x_{F}^{*}$;

(iii) Under the FP rule, F's level of investment, $x_{F}^{F P}$, will be excessive: $x_{F}^{F P}>x_{F}^{*}$; 
(iv) Under the FL rule, F's level of investment, $x_{F}^{F L}$, will be even more excessive: $x_{F}^{F L}>x_{F}^{F P}>x_{F}^{*}$.

Remarks: The intuition for the different parts of this proposition is as follows:

(i) RP rule: R's property right allows it to extract value from $\mathrm{F}$ for allowing $\mathrm{F}$ to operate. Specifically, in both scenarios FR and F, R will allow F to operate in exchange for part of F's profits. Since F can expect to capture only part of the benefits from F's ex ante investment, F will invest too little.

This result, and a similar result in the next proposition, are similar to the standard results in the literature on hold-up problems: when the value produced by a given party is subject to a hold-up by another party, the given party will under-invest.

(ii) RL rule: The value of F's operation, $V_{F}$, enters into the social objective function in scenarios FR and F in which F will operate. In these scenarios, F has to pay damages to R, but these payments - of $H$ in scenario FR and of $V_{R}$ in scenario $\mathrm{F}$ - do not depend on $V_{F}$. Therefore, $\mathrm{F}$ will be the "residual claimant," will get the excess of $V_{F}$ over these payments, and will thus have optimal incentives on the margin.

(iii) FP rule: F's property right will enable $\mathrm{F}$ to extract some positive value also in scenario R, in which it is efficient for F to shut down. Specifically, F will get in scenario R, in return for shutting down and allowing $\mathrm{R}$ to operate, an amount of $V_{F}+(1-\phi)\left(\min \left(H, V_{R}\right)-V_{F}\right)$. Thus, in scenario $\mathrm{R}, \mathrm{F}$ will benefit from a higher $V_{F}$ even though it would provide no social value. Therefore, because a higher $V_{F}$ will provide $\mathrm{F}$ with some private benefit not reflecting social gain, F will invest excessively.

This result is similar to those in the law and economics literature showing that, in some contexts, compensation for a value that is not going to be realized might lead to over- 
investment. For example, Shavell (1980) shows that an expectations remedy will lead to overinvestment in reliance, because the relying party will disregard the possibility that the investment will not produce social value if the contract is not performed. Similarly, Cooter (1985) and Kaplow (1986) suggest that full compensation for government takings leads to over-investment because parties will disregard the possibility that their investment will not produce a social value if their property is taken by the government.

(iv) FL rule: In scenario $R$, in which it is efficient for $F$ to shut down (as F will do), the damage payment awarded to $\mathrm{F}$ will equal $V_{F}$. Therefore, $\mathrm{F}$ will benefit from a higher $V_{F}$ even in scenario $\mathrm{R}$ in which this investment has no social value. Furthermore, whereas under $\mathrm{FP}$ it receives only a fraction of the rise in $V_{F}$, under $\mathrm{FL} \mathrm{F}$ receives the entire marginal increase in $V_{F}$. Thus, the distortion in F's incentives in the direction of excessive investment is more severe under the FL rule than under the FP rule.

\section{$B$. R's Ex ante Investment in Enhancing $V_{R}$}

\section{The Optimal Investment Level}

In setting $x_{R}$, the social objective is to maximize:

$$
\left(P^{F R}+P^{F}\right) \cdot \bar{V}_{F}\left(x_{F}\right)+\left(P^{F R}+P^{R}\right) \cdot \bar{V}_{R}\left(x_{R}\right)-x_{F}-x_{R}-P^{F R} \cdot \bar{H}
$$

The optimal level of $x_{R}, x_{R}^{*}$, is thus the one that maximizes

$$
\left(P^{F R}+P^{R}\right) \cdot \bar{V}_{R}\left(x_{R}\right)-x_{R},
$$

and we can state:

Lemma 5: The optimal level of $x_{R}, x_{R}^{*}$, is characterized by -

(2) $\left(P^{\mathrm{FR}}+P^{\mathrm{R}}\right) \cdot \bar{V}_{R}^{\prime}\left(x_{R}^{*}\right)=1$ 
Remark: The intuition for this lemma is that it is socially desirable to increase $x_{R}$ as long as the marginal utility from such an increase, $\left(P^{\mathrm{FR}}+P^{\mathrm{R}}\right) \cdot \bar{V}_{R}^{\prime}\left(x_{R}\right)$, is larger than the marginal cost of 1 . The $\left(P^{\mathrm{FR}}+P^{\mathrm{R}}\right)$ multiplier in equation (2) reflects the fact that only in two out of the three possible scenarios $\mathrm{R}$ should and will actually operate.

\section{Investment Levels under the Four Alternative Rules}

\section{Proposition 2:}

(i) Under the RP rule, R's level of investment, $x_{R}^{R P}$, will be excessive: $x_{R}^{R P}>x_{R}^{*}$;

(ii) Under the RL rule, R's level of investment, $x_{R}^{R L}$, will be excessive and to an even greater extent than under the RP rule: $x_{R}^{R L}>x_{R}^{R P}>x_{R}^{*}$;

(iii) Under the FP rule, R's level of investment, $x_{R}^{F P}$, will be sub-optimal: $x_{R}^{F P}<x_{R}^{*}$;

(iv) Under the FL rule, R's level of investment, $x_{R}^{F L}$, will be optimal: $x_{R}^{F L}=x_{R}^{*}$.

Remarks: The intuition for this result, which is proved in the appendix, is as follows:

(i) RP rule: R's property right enables $\mathrm{R}$ to extract value from $\mathrm{F}$ in scenario $\mathrm{F}$ in which it is efficient for $\mathrm{R}$ to shut down (as $\mathrm{R}$ will do). Furthermore, the amount that $\mathrm{R}$ will extract will be increasing in $V_{R}$. Therefore, because $\mathrm{R}$ will derive a private benefit from increasing $V_{R}$ even in scenario $\mathrm{R}$ in which such an increase will have no social value, $\mathrm{R}$ will invest excessively.

(ii) RL rule: Under this rule, a higher $V_{R}$ will provide value to $\mathrm{R}$ also in scenario $\mathrm{F}$ (by increasing the damage award $\mathrm{R}$ will get in this scenario) in which $V_{R}$ will not have social value. Therefore, R's investment will be excessive. Furthermore, whereas under the RL rule R 
will receive in scenario $\mathrm{F}$ the entire marginal increase in $V_{R}$, under the $\mathrm{RP}$ rule $\mathrm{R}$ will receive only a fraction of the rise in $V_{R}$. For this reason the distortion in R's incentives is more severe under the RL rule.

(iii) FP rule: Under this rule, in scenario $\mathrm{R}$ in which $\mathrm{F}$ will shut down, if $V_{R}<H$, then $\mathrm{F}$ will be able to extract an amount that will be increasing in $V_{R}$. Consequently, $\mathrm{R}$ will have sub-optimal incentives to invest in enhancing $V_{R}$.

(iv) FL rule: Under this rule, $\mathrm{R}$ will operate in scenario $\mathrm{R}$, as is efficient for $\mathrm{R}$ to do, and will pay damages of $V_{F}$. Since the damage award will not depend on $V_{R}, \mathrm{R}$ will be the "residual claimant," getting the excess of $V_{R}$ over the damage award of $V_{F}$, and R will thus have optimal incentives on the margin.

Putting together the results of propositions 1 and 2, Table 6 summarizes the relative levels of $x_{F}$ and $x_{R}$ under the four different rules.

Table 6: Comparison of Value-Enhancing Investments under the Four Rules

\begin{tabular}{|c|c|c|}
\hline The Legal Rule & F's Investment in $V_{F}$ & R's Investment in $V_{R}$ \\
\hline RP & Sub-optimal: $x_{F}^{R P}<x_{F}^{*}$ & Excessive: $x_{R}^{R P}>x_{R}^{*}$ \\
\hline RL & Optimal: $x_{F}^{R L}=x_{F}^{*}$ & Most Excessive: $x_{R}^{R L}>x_{R}^{R P}>x_{R}^{*}$ \\
\hline FP & Excessive: $x_{F}^{F P}>x_{F}^{*}$ & Sub-optimal: $x_{R}^{F P}<x_{R}^{*}$ \\
\hline FL & Most Excessive: $x_{F}^{F L}>x_{F}^{F P}>x_{F}^{*}$ & Optimal: $x_{R}^{F L}=x_{R}^{*}$ \\
\hline
\end{tabular}

As the above table indicates, none of the four rules can generally induce the optimal level of both $x_{F}$ and $x_{R}$ : The two property right rules, RP and FP lead to both parties investing 
inefficiently, with the party with the property right investing excessively and the other party investing suboptimally. Under the two liability rules, RL and FL, the party without the entitlement will invest optimally, but the party with the entitlement will invest even more excessively than under the property rights rule.

\section{Ex ante Investments in Harm-Reduction}

\section{The Optimal Investment Levels}

Based on the analysis of optimal outcomes in section III, the social objective, in setting $y_{F}$ and $y_{R}$, is to maximize:

$$
P^{F R} \cdot E\left[V_{F}+V_{R}-H-y_{F}-y_{R}\right]+P^{F} \cdot E\left[V_{F}-y_{F}-y_{R}\right]+P^{R} \cdot E\left[V_{R}-y_{F}-y_{R}\right]
$$

or

$$
-y_{F}-y_{R}-P^{F R} \cdot \bar{H}\left(y_{F}, y_{R}\right)+\left(P^{F R}+P^{F}\right) \cdot \bar{V}_{F}+\left(P^{F R}+P^{R}\right) \cdot \bar{V}_{R}
$$

Thus, the optimal level of $y_{F}, y_{F}^{*}$, is the one that minimizes:

$$
y_{F}+P^{F R} \cdot \bar{H}\left(y_{F}, y_{R}\right)
$$

Similarly, the optimal level of $y_{R}, y_{R}^{*}$, is the one that minimizes:

$$
y_{R}+P^{F R} \cdot \bar{H}\left(y_{F}, y_{R}\right)
$$

Based on these observations, I obtain the following result:

\section{Lemma 6:}

(i) For any given level of $y_{R}$, the optimal level of $y_{F}, y_{F}^{*}\left(y_{R}\right)$, is characterized by

$$
\text { (3) } P^{\mathrm{FR}} \cdot \bar{H}_{y_{F}}^{\prime}\left(y_{F}^{*}\left(y_{R}\right), y_{R}\right)=-1
$$

(ii) For any given level of $y_{F}$, the optimal level of $y_{R}, y_{R}^{*}\left(y_{F}\right)$, is characterized by 
(4) $P^{\mathrm{FR}} \cdot \bar{H}_{y_{R}}^{\prime}\left(y_{F}, y_{R}^{*}\left(y_{F}\right)\right)=-1$

Remarks: The intuition for this lemma is as follows:

(i) It is socially desirable to increase $y_{F}$ as long as the marginal utility from such an increase, $\left|P^{\mathrm{FR}} \cdot \bar{H}_{y_{F}}^{\prime}\left(y_{F}(y), y_{R}\right)\right|$, is larger than the marginal cost of 1 . The $P^{F R}$ multiplier reflects the fact that the harm will be born only in scenario FR, where $\min \left(V_{F}, V_{R}, H\right)=H$.

(ii) The intuition for part (ii) is similar to that for part (i) of the lemma.

\section{Investments under the Four Alternative Rules}

Proposition 3: Under the RP rule:

(i) F's level of investment, $y_{F}^{R P}$, will be sub-optimal: $y_{F}^{R P}<y_{F}^{*}$;

(ii) R's level of investment, $y_{R}^{R P}$, will be sub-optimal: $y_{R}^{R P}<y_{R}^{*}$.

Remarks: The intuition for this result, which is proved in the appendix, is as follows:

(i) The relevant scenario is scenario FR, where the harm is actually borne. R's property right allows it to extract value from $\mathrm{F}$ for allowing him to operate. The surplus in the bargaining game of scenario FR equals: $V_{F}-H$. F's investment increases this surplus, but $\mathrm{F}$ receives only a portion of this increase. Therefore, $\mathrm{F}$ will not invest enough in reducing the harm.

(ii) The intuition behind part (ii) resembles the intuition for part (i) of the proposition. R's investment increases the surplus in scenario FR, but $\mathrm{R}$ receives only a portion of this increase. Therefore, $\mathrm{R}$ will not invest enough in reducing the harm. 
Proposition 4: Under the RL rule:

(i) F's level of investment, $y_{F}^{R L}$, will be optimal: $y_{F}^{R L}=y_{F}^{*}$;

(ii) $\mathrm{R}$ will not invest in harm-reduction: $y_{R}^{R L}=0<y_{R}^{*}$.

Remarks: The intuition for this result, which is proved in the appendix, is as follows:

(i) The harm $H$ enters into the social objective function only in scenario FR in which the harm is actually borne. In this scenario, $\mathrm{F}$ has to pay $\mathrm{R}$ damages of $H$. Hence, $\mathrm{F}$ will have incentives to invest optimally.

(iii) R has no incentive to reduce $H$. Specifically, in scenario FR, where $\mathrm{R}$ bears the harm and it is efficient to reduce the level of the harm, $\mathrm{R}$ receives full compensation, and thus does not benefit from investing in lowering $H$.

The results from this proposition are similar to the results in the torts literature (see Shavell (1987, Ch.2)) that, when injurers are strictly liable for victims' losses, injurers will invest optimally in precautions and victims will not invest at all in precautions.

Proposition 5: Under the FP rule:

(i) F will not invest in harm-reduction: $y_{F}^{F P}=0<y_{F}^{*}$.

(ii) R's level of investment, $y_{R}^{F P}$, will be excessive: $y_{R}^{F P}>y_{R}^{*}$.

Remarks: The intuition for this result, which is proved in the appendix, is as follows:

(i) F has no incentive to reduce $H$. Specifically, in scenario FR, where the harm $\mathrm{H}$ is actually borne and reducing $\mathrm{H}$ provides a social benefit, $\mathrm{F}$ enjoys a property right to operate and harm R. Moreover, in scenario $\mathrm{R}$, where $\mathrm{F}$ shuts down, a higher $H$ may improve F's bargaining position as it extracts value from $\mathrm{R}$ in return for shutting down. 
(ii) In scenario $\mathrm{R}$ where $\mathrm{F}$ exploits its property right in return for shutting down, a lower $H$ may improve R's bargaining position. Therefore, $\mathrm{R}$ has excessive incentives to lower $H$.

It is worthwhile highlighting the lack of symmetry between the FP and RP rules is apparent. The reason for this asymmetry lies in the value protected by the property right. While the RP rule protects R's right to operate free of harm, the FP rule protects F's right to operate and cause harm. Basically, the value, to R, of the protection RP offers is $H$ (or $V_{R}$ in scenario F), while the value, to F, of the protection FP offers is

Proposition 6: Under the FL rule:

(i) F will not invest in harm-reduction: $y_{F}^{F L}=0<y_{F}^{*}$.

(ii) R's level of investment, $y_{R}^{F L}$, will be optimal: $y_{R}^{F L}=y_{R}^{*}$.

Remarks: The intuition for this result, which is proved in the appendix, is as follows:

(i) Under the FL rule, F receives $V_{F}$ in all three scenarios. Hence, it has no incentive to invest in reducing $H$.

(ii) The level of the harm affects $\mathrm{R}$ only in scenario FR in which the harm occurs. Furthermore, $\mathrm{R}$ fully bears $H$ in this scenario. Therefore, the FL rule generates accurate incentives for R. Note that the results of this proposition are similar to those in the torts literature. This literature has shown that, when injurers face no liability, injurers will not invest at all in precautions but victims will invest optimally (see Shavell(1987, Ch. 2)).

Putting together the results from propositions 3-6, Table 7 summarizes the relative levels of $y_{F}$ and $y_{R}$ under the four different rules. 
Table 7: Comparison of Investments in Harm-Reduction under the Four Rules

\begin{tabular}{|c|c|c|}
\hline The Legal Rule & $\begin{array}{c}\text { F's Investment } \\
\text { in Reducing } H\end{array}$ & $\begin{array}{c}\text { R's Investment } \\
\text { in Reducing } H\end{array}$ \\
\hline RP & Sub-optimal: $y_{F}^{R P}<y_{F}^{*}$ & Sub-optimal: $y_{R}^{R P}<y_{R}^{*}$ \\
\hline RL & Optimal: $y_{F}^{R L}=y_{F}^{*}$ & Zero: $y_{R}^{R L}=0<y_{R}^{R P}$ \\
\hline FP & Zero: $y_{F}^{F P}=0<y_{F}^{R P}$ & Excessive: $y_{R}^{F P}>y_{R}^{*}$ \\
\hline FL & Zero: $y_{F}^{F L}=0<y_{F}^{R P}$ & Optimal: $y_{R}^{F L}=y_{R}^{*}$ \\
\hline
\end{tabular}

As the table indicates, none of the rules can generally ensure that both $\mathrm{F}$ and $\mathrm{R}$ will invest optimally in harm-reduction. 


\section{Overall Comparison of the Four Alternative Rules}

Table 8: Overall Comparison of Ex ante Investments under the Four Rules

\begin{tabular}{|c|c|c|c|c|}
\hline $\begin{array}{c}\text { The Legal } \\
\text { Rule }\end{array}$ & $\begin{array}{l}\text { F's Investment } \\
\text { in Enhancing } V_{F}\end{array}$ & $\begin{array}{l}\text { R's Investment } \\
\text { in Enhancing } V_{R}\end{array}$ & $\begin{array}{l}\text { F's Investment } \\
\text { in Reducing } H\end{array}$ & $\begin{array}{l}\text { R's Investment } \\
\text { in Reducing } H\end{array}$ \\
\hline $\mathrm{RP}$ & $\begin{array}{l}\text { Sub-optimal } \\
x_{F}^{R P}<x_{F}^{*}\end{array}$ & $\begin{array}{l}\text { Excessive } \\
x_{R}^{R P}>x_{R}^{*}\end{array}$ & $\begin{array}{l}\text { Sub-optimal } \\
y_{F}^{R P}<y_{F}^{*}\end{array}$ & $\begin{array}{l}\text { Sub-optimal } \\
y_{R}^{R P}<y_{R}^{*}\end{array}$ \\
\hline $\mathrm{RL}$ & $\begin{array}{l}\text { Optimal } \\
x_{F}^{R L}=x_{F}^{*}\end{array}$ & $\begin{array}{l}\text { Most Excessive } \\
x_{R}^{R L}>x_{R}^{R P}>x_{R}^{*}\end{array}$ & $\begin{array}{l}\text { Optimal } \\
y_{F}^{R L}=y_{F}^{*}\end{array}$ & $\begin{array}{c}\text { Zero } \\
y_{R}^{R L}=0<y_{R}^{R P}\end{array}$ \\
\hline FP & $\begin{array}{l}\text { Excessive } \\
\qquad x_{F}^{F P}>x_{F}^{*}\end{array}$ & $\begin{array}{c}\text { Sub-optimal } \\
x_{R}^{F P}<x_{R}^{*}\end{array}$ & $\begin{array}{c}\text { Zero } \\
y_{F}^{F P}=0<y_{F}^{R P}\end{array}$ & $\begin{array}{l}\text { Excessive } \\
y_{R}^{F P}>y_{R}^{*}\end{array}$ \\
\hline$\overline{\mathrm{FL}}$ & $\begin{array}{l}\text { Most Excessive } \\
x_{F}^{F L}>x_{F}^{F P}>x_{F}^{*}\end{array}$ & $\begin{array}{l}\text { Optimal } \\
x_{R}^{F L}=x_{R}^{*}\end{array}$ & $\begin{array}{c}\text { Zero } \\
y_{F}^{F L}=0<y_{F}^{R P}\end{array}$ & $\begin{array}{l}\text { Optimal } \\
y_{R}^{F L}=y_{R}^{*}\end{array}$ \\
\hline
\end{tabular}

As the table above indicates, none of the rules can ensure that all ex ante investments will be made at the efficient level. Each rule will cause for at least two of the ex ante investments to be made at an inefficient level. Still, the rules might well differ in the overall expected efficiency costs produced by each of them, and the best rule from the perspective of ex ante investments is the one that produces the lowest level of such costs.

With this in mind, I will comment on two main choices that policymakers face and must make: (i) which side should get the entitlement, and (ii) which form of protection should be given to the entitlement. Let us start with choice (ii). 


\section{Protection by a Property Right vs. Protection by a Liability Rule}

One important contribution of the existing literature has been to identify certain important ex post advantages that liability rules have when ex post bargaining is easy. If ex post bargaining is to fail, the party not having the entitlement would likely make a less efficient decision when faced with an infinite price (which is what a property right to the other side would imply in the absence of an agreement) than with a price equal to a court's estimate (even if this estimate is somewhat erroneous) of the damage to the other side. In their important study, Kaplow and Shavell conclude that there is a prime facie case for favoring liability rules over property rights (1996, at 721), but they list several factors (investments by victim in reducing potential harm being one of them) that might still make property rights desirable. As I show below, from the perspective of ex ante effects, liability rules do not have a systematic advantage. A liability rule protection might or might not be superior to a property right protection from the perspective of ex ante incentives.

For concreteness, let us suppose that we wish to afford $\mathrm{R}$ protection against F's polluting the water, and the only choice is whether to protect this entitlement of $\mathrm{R}$ with a property right or with a liability rule - that is, the choice between RL and RP. The results summarized in Table 8 indicate that RL is not generally superior to RP. Rather, the following observations can be made with respect to how RL and RP compare:

- $\mathrm{RL}$ is superior to RP in terms of F's investments both in enhancing $V_{F}$ and in reducing $H$ : whereas $\mathrm{RL}$ induces $\mathrm{F}$ to choose optimal levels for both investments, RL results in sub-optimal levels for both investments;

- However, RL is inferior to RP in terms of R's investments both in enhancing $V_{R}$ and in reducing $H$ : (i) both rules result in excessive investment in enhancing $V_{R}$, but the extent to 
which the investment is excessive is greater under RL; and (ii) R's investment in reducing $H$ is zero under RL but positive (though still sub-optimal) under RP.

Which rule will be superior will depend on the balance of the above efficiency costs. Algebraic rearrangement makes it possible to state this point formally in the form of the following Corollary.

Corollary 1: RP will be superior to RL if and only if:

$$
\begin{aligned}
&\left\{\left(P^{F R}+P^{F}\right) \cdot\left[\bar{V}_{F}\left(x_{F}^{R L}\right)-\bar{V}_{F}\left(x_{F}^{R P}\right)\right]-\left(x_{F}^{R L}-x_{F}^{R P}\right)\right\}+\left\{\left(P^{F R}+P^{R}\right) \cdot\left[\bar{V}_{R}\left(x_{R}^{R P}\right)-\bar{V}_{R}\left(x_{R}^{R L}\right)\right]-\left(x_{R}^{R P}-x_{R}^{R L}\right)\right\}+ \\
&\left\{-P^{F R} \cdot\left[\bar{H}\left(y_{F}^{R P}, y_{R}^{R P}\right)-\bar{H}\left(y_{F}^{R L}, y_{R}^{R L}\right)\right]-\left(y_{F}^{R P}-y_{F}^{R L}\right)-\left(y_{R}^{R P}-y_{R}^{R L}\right)\right\}>0
\end{aligned}
$$

Remark: The three terms on the left-hand side of the inequality compare the efficiency properties of the two rules with respect to investments in enhancing $V_{F}$, enhancing $V_{R}$ and reducing $H$. The first term represents the advantage of RL in connection with $x_{F}$. The second term represents the advantage of RP in connection with $x_{R}$. The third term compares the two rules in connection with $y_{F}$ and $y_{R}$ (since RL is superior in connection with $y_{F}$ but RP is superior in connection with $y_{R}$, the sign of the third term cannot be generally determined).

Policymakers wishing to take ex ante efficiency considerations into account should assess, for any given category of cases, the relative magnitudes of the factors identified above . The following brief observations concern the circumstances that would make one of the two rules likely to be superior:

- If it is more important to reduce deviations of R's investments from their efficient levels than to reduce deviations of F's investments from their efficient levels, then RP will tend to be superior to RL. For example, if it is very important to have R make some investments in harm-reduction, then RP would likely be superior to RL, since RL will lead to zero such investments whereas RP will induce some such investment. 
- Conversely, if it is more important to reduce deviations from optimal investments by $\mathrm{F}$ than it is to reduce deviations from optimal investments by R, then RL will tend to be superior to RP. For example if, it is very important to induce optimal investments by $\mathrm{F}$ in enhancing the value of its activity, then RL would likely be superior to RP, since RP will induce suboptimal level of such investment, whereas RL will induce an optimal level.

- If scenario $\mathrm{F}$ is most likely (that is, if $P^{F}$ is sufficiently large), then RL will tend to be superior to RP. Supposing that in all likelihood R will not engage in its activity, then investments in reducing $\mathrm{H}$ would be of little importance, as would be investments in enhancing $V_{R}$. In this case, what would be most important would be inducing an optimal investment in $V_{F}$, which RL but not RP would accomplish.

\section{Should the Entitlement Go to F or to R?}

Next, let us consider the choice of which side should get the entitlement. For example, let us suppose that we are going to give the party with the entitlement a property rights protection, and let us consider the choice between giving the entitlement to $\mathrm{R}$ and to $\mathrm{F}$ - that is, the choice between FP and RP.

Again, the results summarized in Table 8 indicate that neither of the two rules generally dominates the other in terms of ex ante incentives. The following observations describe how FP and RP compare:

- With respect to F's investment in $V_{F}$, RP will lead to sub-optimal investment and FP will lead to excessive investment.

- With respect to R's investment in $V_{R}$, the reverse will be the case: FP will lead to suboptimal investment and RP will lead to excessive investment. 
- With respect to F's investment in reducing $H$, RP will be superior because FP will lead to zero investment whereas RP will lead to a positive (though still sub-optimal) investment.

- With respect to R's investment in reducing $H$, RP will lead to sub-optimal investment whereas FP will lead to excessive investment.

Which rule will be superior will depend on the balance of the above efficiency costs. As before, algebraic rearrangement makes it possible to state this point formally in the form of the following Corollary.

Corollary 2: RP will be superior to FP if and only if:

$$
\begin{aligned}
& \left\{\left(P^{F R}+P^{F}\right) \cdot\left[\bar{V}_{F}\left(x_{F}^{R P}\right)-\bar{V}_{F}\left(x_{F}^{F P}\right)\right]-\left(x_{F}^{R P}-x_{F}^{F P}\right)\right\}+\left\{\left(P^{F R}+P^{R}\right) \cdot\left[\bar{V}_{R}\left(x_{R}^{R P}\right)-\bar{V}_{R}\left(x_{R}^{F P}\right)\right]-\left(x_{R}^{R P}-x_{R}^{F P}\right)\right\}+ \\
& \left\{-P^{F R} \cdot\left[\bar{H}\left(y_{F}^{R P}, y_{R}^{R P}\right)-\bar{H}\left(y_{F}^{F P}, y_{R}^{F P}\right)\right]-\left(y_{F}^{R P}-y_{F}^{F P}\right)-\left(y_{R}^{R P}-y_{R}^{F P}\right)\right\}>0
\end{aligned}
$$

Remark: As in Corollary 1, the three terms on the left hand side of the inequality compare the efficiency properties of the two rules with respect to investments in enhancing $V_{F}$, enhancing $V_{R}$ and reducing $H$. Here, however, none of the signs of the three terms can be generally determined.

The above analysis indicates the considerations that policy-makers must assess in order to determine how RP and FP compare with respect to ex ante efficiency. The following brief observations can be made as to the circumstances that would make one of the two rules likely superior:

- The more important it is to avoid under-investment by $\mathrm{F}$ in $V_{F}$, the more one should lean toward FP.

- The more important it is to avoid under-investment by $\mathrm{R}$ in $V_{R}$, the more one should lean toward RP. 
- The more important it is for $\mathrm{F}$ to invest some positive amount in reducing $H$, the more one should lean toward RP.

- The more important it is to avoid under-investment in R's harm-reduction investment, the more one should lean toward FP.

\section{GOVERNMENT FINES}

The preceding analysis has shown that none of the considered rules can attain the firstbest. Each rule produces some efficiency costs, with at least one of the parties not making optimal ex ante investments. Indeed, the logic of the results suggests that any allocation of entitlements between the two parties - any method of dividing the total value produced by the two activities between the two parties - would result in some ex ante inefficiencies. ${ }^{12}$ There appears to be no way to divide the ex post value so that each party will on the margin get exactly the social value generated by its investments. ${ }^{13}$

In theory, there is a way in which the first-best could be attained by introducing the government as a third player through the imposition of government fines. Suppose that the government could at $\mathrm{T}=2$ observe without R's help both whether F operates and the level of damages to $\mathrm{R}$ from F's operations, which is $\min \left(V_{R}, H\right)$. And consider a Government Fine (GF) rule under which, if $\mathrm{F}$ operates, F must pay a fine to the government equal to the social

\footnotetext{
12 This applies, for example, to the large family of creative rules studied by Ayres and Goldblat (2001) and Avraham (2001).

${ }^{13}$ This sort of problem is familiar to students of law and economics from other contexts. For an excellent general discussion of it, see Cooter (1985). Although Cooter identifies that this problem arises in a number of contexts, he does not see that, in the presence of ex ante investments, it also arises in the context studied in this paper. Indeed, examining the context of nuisance, Cooter suggests that such a problem does not arise when injunctive relief (i.e., a property right) is used. In discussing the problem of victims ex ante incentives to mitigate harm, Kaplow and Shavell (1996, p. 738) note that a legal rule compelling injurers (parties creating externalities) to make payments to the state rather than victims will provide victims with incentives to mitigate harm.
} 
cost of F's activity, i.e. $\min \left(V_{R}, H\right)$. In this case, when both parties engage in their activities, each one of them will fully bear the cost $H$ resulting from the joint presence of the activities. Consequently, as the next result indicates, each side will make the socially optimal decisions with respect to ex ante actions.

Proposition 7: Under the GF rule:

(i) F's levels of investment, both in raising $V_{F}$ and in lowering $H$, will be equal to the socially optimal levels, $x_{F}^{*}$ and $y_{F}^{*}$.

(ii) R's level of investment, both in raising $V_{R}$ and in lowering $H$, will be equal to the socially optimal levels, $x_{R}^{*}$ and $y_{R}^{*}$.

Remarks: The intuition for this result, which is proved in the appendix, is as follows:

The GF rule makes use of the efficient aspects of both the RL and FL rules -

(i) The GF rule places $F$ in the same position as $F$ would be in under the RL rule. As shown in propositions 1 and $4, \mathrm{~F}$ behaves optimally in this position.

(ii) The GF rule places $\mathrm{R}$ in the same position as $\mathrm{R}$ would be in under the FL rule. As shown in propositions 2 and $6, \mathrm{R}$ behaves optimally in this position.

The efficiency of the GF rule thus stems from its ability to combine the good halves of both the RL and FL rules. It is able to do so, since it is not confined to the division of value between $\mathrm{F}$ and $\mathrm{R}$. The inclusion of a third party, the government, alleviates this restriction.

Although fines are sometimes used, application of the GF rule is far from universal. One important reason might be that the assumptions of the above analysis often do not hold. First, there is a problem in triggering the GF rule. Why should $\mathrm{R}$ report F's externality, if $\mathrm{R}$ cannot expect any compensation? A second problem also concerns R's willingness to cooperate. 
Recall that in scenario $\mathrm{F}$ the operation of the GF rule requires an assessment of the damages $\min \left(V_{R}, H\right)$. Under the GF rule there is no reason to expect R's cooperation in evaluating these damages; on the contrary, F and R might agree for $\mathrm{R}$, in return for a side payment, to do whatever possible to push down the estimated damages.

\section{CONCLUSION}

This paper has analyzed the ex ante effects of allocations of entitlements, focusing on the case in which ex post bargaining is easy. Alternative rules have been shown to have a range of different ex ante effects, both on the investments made by each side to enhance the value of its activities and on the investments made by each side to reduce the harm that would result in case of conflicting use. From the perspective of ex ante considerations, liability rules do not generally dominate property rights. By analyzing how the main alternative rules affect each of these ex ante investments, the paper has provided a framework for assessing alternative rules from the perspective of ex ante incentives. Such assessment should be an important element in the design of property rights and liability rules. 


\section{APPENDIX}

\section{Proof of Proposition 1:}

(i) Under the RP rule, F's expected payoff is:

$$
P^{F R} \cdot E\left[(1-\phi)\left(V_{F}-H\right)-x_{F}\right]+P^{F} \cdot E\left[(1-\phi)\left(V_{F}-V_{R}\right)-x_{F}\right]+P^{R} \cdot E\left[0-x_{F}\right]
$$

or

$$
\left(P^{F R}+P^{F}\right) \cdot(1-\phi) \cdot \bar{V}_{F}\left(x_{F}\right)-x_{F}-P^{F} \cdot(1-\phi) \cdot \bar{V}_{R}\left(x_{R}\right)-P^{F R} \cdot(1-\phi) \cdot \bar{H}
$$

Due to the additive nature of the objective function, F's decision regarding $x_{F}$ is determined only by the first two terms. Therefore, F will choose a level of investment that satisfies the following first-order condition:

$$
\text { (A1) }\left(P^{F R}+P^{F}\right) \cdot(1-\phi) \cdot \bar{V}_{F}^{\prime}\left(x_{F}^{R P}\right)=1
$$

Comparing equations (1) and (A1), and recalling the diminishing returns assumption, we obtain $x_{F}^{R P}<x_{F}^{*}$.

(ii) Under the RL rule, F's expected payoff is:

$$
P^{F R} \cdot E\left[V_{F}-H-x_{F}\right]+P^{F} \cdot E\left[V_{F}-V_{R}-x_{F}\right]+P^{R} \cdot E\left[0-x_{F}\right]
$$

or

$$
\left(P^{F R}+P^{F}\right) \cdot \bar{V}_{F}\left(x_{F}\right)-x_{F}-P^{F} \cdot \bar{V}_{R}\left(x_{R}\right)-P^{F R} \cdot \bar{H}
$$

Due to the additive nature of the objective function, the first-order condition, which determines F's ex ante investment, is identical to equation (1), implying that $x_{F}^{R L}=x_{F}^{*}$.

(iii) Let $\alpha \equiv \operatorname{Pr}\left(V_{R}<H \mid \min \left(V_{F}, V_{R}, H\right)=V_{F}\right)$. Under the FP rule, F's expected payoff is:

$$
P^{F R} \cdot E\left[V_{F}-x_{F}\right]+P^{F} \cdot E\left[V_{F}-x_{F}\right]+P^{R} \cdot\left\{(1-\alpha) \cdot E\left[\phi V_{F}+(1-\phi) H-x_{F}\right]+\alpha \cdot E\left[\phi V_{F}+(1-\phi) V_{R}-x_{F}\right]\right\}
$$

or 


$$
\left(P^{F R}+P^{F}+\phi P^{R}\right) \cdot \bar{V}_{F}\left(x_{F}\right)-x_{F}+(1-\phi) P^{R} \cdot\left((1-\alpha) \cdot \bar{H}+\alpha \cdot \bar{V}_{R}\left(x_{R}\right)\right)
$$

Due to the additive nature of the objective function, F's decision is determined only by the first two terms. Therefore, F will choose a level of investment that satisfies the following first-order condition:

$$
\text { (A2) }\left(P^{F R}+P^{F}+\phi P^{R}\right) \cdot \bar{V}_{F}^{\prime}\left(x_{F}^{F P}\right)=1
$$

Comparing equations (1) and (A2), and recalling the diminishing returns assumption, we obtain $x_{F}^{F P}>x_{F}^{*}$.

(iv) Under the FL rule, F's expected payoff is:

$$
P^{F R} \cdot E\left[V_{F}-x_{F}\right]+P^{F} \cdot E\left[V_{F}-x_{F}\right]+P^{R} \cdot E\left[V_{F}-x_{F}\right]
$$

or

$$
\bar{V}_{F}\left(x_{F}\right)-x_{F}
$$

Therefore, F will choose a level of investment that satisfies the following first-order condition:

$$
\text { (A3) } \bar{V}_{F}^{\prime}\left(x_{F}^{F L}\right)=1
$$

Comparing equations (1) and (A3), and recalling the diminishing returns assumption, we obtain $x_{F}^{F L}>x_{F}^{*}$.

QED

\section{Proof of Proposition 2:}

(i) Under the RP rule, R's expected payoff is:

$$
P^{F R} \cdot E\left[V_{R}+\phi\left(V_{F}-H\right)-x_{R}\right]+P^{F} \cdot E\left[V_{R}+\phi\left(V_{F}-V_{R}\right)-x_{R}\right]+P^{R} \cdot E\left[V_{R}-x_{R}\right]
$$

or

$$
\left(1-P^{\mathrm{F}} \cdot \phi\right) \cdot \bar{V}_{R}\left(x_{R}\right)-x_{R}+\left(P^{F R}+P^{F}\right) \cdot \phi \cdot \bar{V}_{F}\left(x_{F}\right)-P^{F R} \cdot \phi \cdot \bar{H}
$$


Due to the additive nature of the objective function, $\mathrm{R}$ 's decision regarding $x_{R}$ is determined only by the first two terms. Therefore, $\mathrm{R}$ will choose a level of investment that satisfies the following first-order condition:

$$
\text { (A4) }\left(1-P^{F} \cdot \phi\right) \cdot \bar{V}_{R}^{\prime}\left(x_{R}^{R P}\right)=1
$$

Since $1-P^{F} \cdot \phi>P^{F R}+P^{R}$, comparing equations (2) and (A4), and recalling the diminishing returns assumption, we obtain $x_{R}^{R P}>x_{R}^{*}$.

(ii) Under the RL rule, R's expected payoff is:

$$
P^{F R} \cdot E\left[V_{R}-x_{R}\right]+P^{F} \cdot E\left[V_{R}-x_{R}\right]+P^{R} \cdot E\left[V_{R}-x_{R}\right]
$$

or

$$
\bar{V}_{R}\left(x_{R}\right)-x_{R}
$$

Therefore, R will choose a level of investment that satisfies the following first-order condition:

$$
\text { (A5) } \bar{V}_{R}^{\prime}\left(x_{R}^{R L}\right)=1
$$

Comparing equations (2) and (A5), and recalling the diminishing returns assumption, we obtain $x_{R}^{R L}>x_{R}^{*}$

(iii) Let $\alpha \equiv \operatorname{Pr}\left(V_{R}<H \mid \min \left(V_{F}, V_{R}, H\right)=V_{F}\right)$. Under the FP rule, R's expected payoff is:

$$
P^{F R} \cdot E\left[V_{R}-H-x_{R}\right]+P^{F} \cdot E\left[0-x_{R}\right]+P^{R} \cdot\left\{(1-\alpha) \cdot E\left[V_{R}-H+\phi\left(H-V_{F}\right)-x_{R}\right]+\alpha \cdot E\left[\phi\left(V_{R}-V_{F}\right)-x_{R}\right]\right\}
$$

or

$$
\left(P^{F R}+P^{R} \cdot(1-\alpha(1-\phi))\right) \cdot \bar{V}_{R}\left(x_{R}\right)-x_{R}-\left(P^{F R}+P^{R}(1-\alpha)(1-\phi)\right) \cdot \bar{H}-\phi P^{R} \cdot \bar{V}_{F}\left(x_{F}\right)
$$

Due to the additive nature of the objective function, $\mathrm{R}$ 's decision is determined only by the first two terms. Therefore, $\mathrm{R}$ will choose a level of investment that satisfies the following first-order condition:

$$
\left(P^{F R}+P^{R} \cdot(1-\alpha(1-\phi))\right) \cdot \bar{V}_{R}^{\prime}\left(x_{R}^{F P}\right)=1
$$


Comparing equations (2) and (A6), and recalling the diminishing returns assumption, we obtain $x_{R}^{F P}<x_{R}^{*}$

(iv) Under the FL rule, R's expected payoff is:

$$
P^{F R} \cdot E\left[V_{R}-H-x_{R}\right]+P^{F} \cdot E\left[0-x_{R}\right]+P^{R} \cdot E\left[V_{R}-V_{F}-x_{R}\right]
$$

or

$$
\left(P^{F R}+P^{R}\right) \cdot \bar{V}_{R}\left(x_{R}\right)-x_{R}-P^{F R} \cdot \bar{H}-P^{R} \cdot \bar{V}_{F}\left(x_{F}\right)
$$

Due to the additive nature of the objective function, $\mathrm{R}$ 's decision is determined only by the first two terms. Hence, the first-order condition, which determines R's ex ante investment, is identical to equation (2), implying that $x_{R}^{F L}=x_{R}^{*}$. QED

\section{Proof of Proposition 3:}

(i) F's expected payoff under the RP rule is:

$$
P^{F R} \cdot E\left[(1-\phi)\left(V_{F}-H\right)-y_{F}\right]+P^{F} \cdot E\left[(1-\phi)\left(V_{F}-V_{R}\right)-y_{F}\right]+P^{R} \cdot E\left[0-y_{F}\right]
$$

or

$$
-y_{F}-(1-\phi) \cdot P^{F R} \cdot \bar{H}\left(y_{F}, y_{R}\right)+(1-\phi) \cdot\left(P^{F R}+P^{F}\right) \cdot \bar{V}_{F}-(1-\phi) \cdot P^{F} \cdot \bar{V}_{R}
$$

Due to the additive nature of the objective function, F's decision regarding $y_{F}$ is determined only by the first two terms. Therefore, F will choose a level of investment that satisfies the following first-order condition:

$$
\text { (A7) }(1-\phi) \cdot P^{\mathrm{FR}} \cdot \bar{H}_{y_{F}}^{\prime}\left(y_{F}^{R P}\left(y_{R}\right), y_{R}\right)=-1
$$

Comparing equations (3) and (A7), and recalling the diminishing returns assumption, we obtain $y_{F}^{R P}<y_{F}^{*}$.

(ii) R's expected payoff is:

$$
P^{F R} \cdot E\left[V_{R}+\phi\left(V_{F}-H\right)-y_{R}\right]+P^{F} \cdot E\left[V_{R}+\phi\left(V_{F}-V_{R}\right)-y_{R}\right]+P^{R} \cdot E\left[V_{R}-y_{R}\right]
$$


or

$$
-y_{R}-\phi \cdot P^{F R} \cdot \bar{H}\left(y_{F}, y_{R}\right)+\left(1-\phi \cdot P^{F}\right) \cdot \bar{V}_{R}+\left(P^{F R}+P^{F}\right) \cdot \phi \cdot \bar{V}_{F}
$$

Due to the additive nature of the objective function, $\mathrm{R}$ 's decision regarding $y_{R}$ is determined only by the first two terms. Therefore, $\mathrm{R}$ will choose a level of investment that satisfies the following first-order condition:

$$
\text { (A8) } \phi \cdot P^{\mathrm{FR}} \cdot \bar{H}_{y_{R}}^{\prime}\left(y_{F}, y_{R}^{R P}\left(y_{F}\right)\right)=-1
$$

Comparing equations (4) and (A8), and recalling the diminishing returns assumption, we obtain $y_{R}^{R P}<y_{R}^{*}$

\section{Proof of Proposition 4:}

(i) F's expected payoff under the RL rule is:

$$
P^{F R} \cdot E\left[V_{F}-H-y_{F}\right]+P^{F} \cdot E\left[V_{F}-V_{R}-y_{F}\right]+P^{R} \cdot E\left[0-y_{F}\right]
$$

or

$$
-y_{F}-P^{F R} \cdot \bar{H}\left(y_{F}, y_{R}\right)+\left(P^{F R}+P^{F}\right) \cdot \bar{V}_{F}-P^{F} \cdot \bar{V}_{R}
$$

Due to the additive nature of the objective function, F's decision regarding $y_{F}$ is determined only by the first two terms. Hence, the first-order condition, which determines F's ex ante investment, is identical to equation (3). This implies $y_{F}^{R L}=y_{F}^{*}$.

(ii) R's expected payoff is:

$$
P^{F R} \cdot E\left[V_{R}-y_{R}\right]+P^{F} \cdot E\left[V_{R}-y_{R}\right]+P^{R} \cdot E\left[V_{R}-y_{R}\right]
$$

or

$$
-y_{R}+\bar{V}_{R}
$$

Solving R's optimization problem, we obtain $y_{R}^{R L}=0<y_{R}^{*}$. 


\section{Proof of Proposition 5:}

Let $\alpha \equiv \operatorname{Pr}\left(V_{R}<H \mid \min \left(V_{F}, V_{R}, H\right)=V_{F}\right)$.

(i) F's expected payoff under the FP rule is:

$P^{F R} \cdot E\left[V_{F}-y_{F}\right]+P^{F} \cdot E\left[V_{F}-y_{F}\right]+P^{R} \cdot\left\{(1-\alpha) \cdot E\left[\phi V_{F}+(1-\phi) H-y_{F}\right]+\alpha \cdot E\left[\phi V_{F}+(1-\phi) V_{R}-y_{F}\right]\right\}$

or

$$
-y_{F}+(1-\phi) P^{R} \cdot(1-\alpha) \cdot \bar{H}\left(y_{F}, y_{R}\right)+\left(P^{F R}+P^{F}+\phi P^{R}\right) \cdot \bar{V}_{F}+(1-\phi) P^{R} \cdot \alpha \cdot \bar{V}_{R}
$$

Solving F's optimization problem, we obtain: $y_{F}^{F P}=0<y_{F}^{*}$. [Note: To avoid some confusion, perhaps it is worth showing (or mentioning) that the implied constraint $y_{F} \geq 0$ is binding? Otherwise, the FOC would seem to be $(1-\Phi)(1-\alpha) P^{R} H^{\prime}{ }_{y F}\left(y_{F}{ }^{F P}\left(y_{R}\right), y_{R}\right)=1$, which is strange first of all because we took $H^{\prime}()<$.0 . And then comparing that apparent FOC with equation (3) for $y_{F}{ }^{*}$ would require comparing $(1-\Phi)(1-\alpha) P^{R}$ against $P^{F R}$, so the relative size of $y_{F}^{F P}$ and $y_{F}{ }^{*}$ would not be obvious.) (ii) R's expected payoff is:

$P^{F R} \cdot E\left[V_{R}-H-y_{R}\right]+P^{F} \cdot E\left[0-y_{R}\right]+P^{R} \cdot\left\{(1-\alpha) \cdot E\left[V_{R}-H+\phi\left(H-V_{F}\right)-y_{R}\right]+\alpha \cdot E\left[\phi\left(V_{R}-V_{F}\right)-y_{R}\right]\right\}$

or

$$
-y_{R}-\left(P^{F R}+P^{R}(1-\alpha)(1-\phi)\right) \cdot \bar{H}\left(y_{F}, y_{R}\right)-\phi P^{R} \cdot \bar{V}_{F}+\left(P^{F R}+P^{R} \cdot(1-\alpha(1-\phi))\right) \cdot \bar{V}_{R}
$$

Due to the additive nature of the objective function, R's decision is determined only by the first two terms. Therefore, $\mathrm{R}$ will choose a level of investment that satisfies the following first-order condition:

$$
\left(P^{F R}+P^{R} \cdot(1-\alpha)(1-\phi)\right) \cdot \bar{H}_{y_{R}}^{\prime}\left(y_{F}, y_{R}^{F P}\left(y_{F}\right)\right)=1
$$

Comparing equations (4) and (A9), and recalling the diminishing returns assumption, we obtain $y_{R}^{F P}>y_{R}^{*}$

QED 


\section{Proof of Proposition 6:}

(i) F's expected payoff under the FL rule is:

$$
P^{F R} \cdot E\left[V_{F}-y_{F}\right]+P^{F} \cdot E\left[V_{F}-y_{F}\right]+P^{R} \cdot E\left[V_{F}-y_{F}\right]
$$

or

$$
-y_{F}+\bar{V}_{F}
$$

Solving F's optimization problem, we obtain $y_{F}^{F L}=0<y_{F}^{*}$.

(ii) R's expected payoff is:

$$
P^{F R} \cdot E\left[V_{R}-H-y_{R}\right]+P^{F} \cdot E\left[0-y_{R}\right]+P^{R} \cdot E\left[V_{R}-V_{F}-y_{R}\right]
$$

or

$$
-y_{R}-P^{F R} \cdot \bar{H}\left(y_{F}, y_{R}\right)-P^{R} \cdot \bar{V}_{F}+\left(P^{F R}+P^{R}\right) \cdot \bar{V}_{R}
$$

Due to the additive nature of the objective function, $\mathrm{R}$ 's decision regarding $y_{R}$ is determined only by the first two terms. Hence, the first-order condition, which determines R's ex ante investment, is identical to equation (4), implying that $y_{R}^{F L}=y_{R}^{*}$. QED

\section{Proof of Proposition 7:}

Let $x_{F}^{G F}$ denote F's ex ante investment in enhancing $V_{F}$ under the GF rule. Similarly, denote by $x_{R}^{G F} \mathrm{R}$ 's ex ante investment in enhancing $V_{R}$ under the GF rule. Also, let $y_{F}^{G F}$ denote F's ex ante investment in reducing $H$ under the GF rule. Similarly, denote by $y_{R}^{G F} \mathrm{R}$ 's ex ante investment in reducing $H$ under the GF rule.

(i) F's expected payoff is:

$$
P^{F R} \cdot E\left[V_{F}-H-x_{F}-y_{F}\right]+P^{F} \cdot E\left[V_{F}-V_{R}-x_{F}-y_{F}\right]+P^{R} \cdot E\left[0-x_{F}-y_{F}\right]
$$

or

$$
\left(P^{F R}+P^{F}\right) \cdot \bar{V}_{F}\left(x_{F}\right)-x_{F}-P^{F} \cdot \bar{V}_{R}\left(x_{R}\right)-y_{F}-P^{F R} \cdot \bar{H}\left(y_{R}, y_{R}\right)
$$


Due to additive nature of the payoff function, F's investment in raising $V_{F}$ is determined only by the first two terms. Hence, the first-order condition that determines $x_{F}^{G F}$ is identical to equation (1). This implies $x_{F}^{G F}=x_{F}^{*}$. Similarly, F's investment in lowering $H$ is determined only by the last two terms. Hence, the first-order condition that determines $y_{F}^{G F}$ is identical to equation (3). This implies $y_{F}^{G F}=y_{F}^{*}$.

(ii) R's expected payoff is:

$$
P^{F R} \cdot E\left[V_{R}-H-x_{R}-y_{R}\right]+P^{F} \cdot E\left[0-x_{R}-y_{R}\right]+P^{R} \cdot E\left[V_{R}-x_{R}-y_{R}\right]
$$

or

$$
\left(P^{F R}+P^{R}\right) \cdot \bar{V}_{R}\left(x_{R}\right)-x_{R}-y_{R}-P^{F R} \cdot \bar{H}\left(y_{R}, y_{R}\right)
$$

Due to additive nature of the payoff function, R's investment in raising $V_{R}$ is determined only by the first two terms. Hence, the first-order condition that determines $x_{R}^{G F}$ is identical to equation (2). This implies $x_{R}^{G F}=x_{R}^{*}$. Similarly, R's investment in lowering $H$ is determined only by the last two terms. Hence, the first-order condition that determines $y_{R}^{G F}$ is identical to equation (4). This implies $y_{R}^{G F}=y_{R}^{*}$.

QED 


\section{REFERENCES}

Aghion, P., M. Dewatripont and P. Rey (1994), "Renegotiation Design with Unverifiable Information," Econometrica, Vol. 62, 257-282.

Aghion P. and J. Tirole (1997), "Formal and Real Authority in Organizations," The Journal of Political Economy, Vol. 105, 1-29.

Avraham, Ronen (2001), "Modular Liability Rules," Discussion Paper 01-003, Olin Center for Law \& Economics, University of Michigan.

Ayres, Ian and Peter Goldblat (2001), " Optimal Delegation and Decoupling in the Design of Liability Rules," Working Paper No. 249, Yale Law School, forthcoming Michigan Law Review_(2001).

Ayres, Ian and Eric Talley (1995), "Solomonic Bargaining: Dividing a Legal Entitlement To Facilitate Coasian Trade," The Yale Law Journal, Vol. 104, 1027-1117.

Bebchuk, Lucian Arye (2001), “Ownership and Exchange,” Working Paper, Harvard University.

Calabresi, Guido and A. Douglas Melamed (1972), "Property Rules, Liability Rules, and Inalienability: One View of the Cathedral," The Harvard Law Review, Vol. 85, 1089-1128.

Chung, T.-Y. (1991), "Incomplete Contracts, Specific Investment and Risk Sharing," The Review of Economic Studies, Vol. 58, 1031-1042.

Coase, Ronald H. (1960), "The Problem of Social Cost," The Journal of Law and Economics, Vol. 3, 1-44.

Cooter, Robert (1985) "Unity in Tort, Contract, and Property: The Model of Precaution," California Law Review, Vol. 73, 1-55.

Edlin, Aaron. S. and Stefan Reichelstein (1996), "Holdups, Standard Breach Remedies, and Optimal Investment," The American Economic Review, Vol. 86, 478-501.

Grossman, Sanford and Oliver D. Hart (1986), "The Costs and Benefits of Ownership: A Theory of Vertical and Lateral Integration," The Journal of Political Economy, Vol. 94, 691-719.

Hart, Oliver (1995), Firms, Contracts, and Financial Structure, Clarendon Press, Oxford.

Hart, Oliver and John Moore (1988), "Incomplete Contracts and Renegotiation," Econometrica, Vol. 56, 755-86.

Hart, Oliver and John Moore (1990), "Property Rights and the Nature of the Firm," The Journal of Political Economy, Vol. 98, 1119-1158. 
Kaplow, Louis (1986), "Economic Analysis of Legal Transition," The Harvard Law Review, Vol. 99, pp. 509-617.

Kaplow, Louis and Steven Shavell (1996), "Property Rules Versus Liability Rules: An Economic Analysis," The Harvard Law Review, Vol. 109, 713-790.

Klein, B., R. Crawford and A. Alchian (1978), "Vertical Integration, Appropriable Rents and the Competitive Contracting Process," The Journal of Law and Economics, Vol. 21, 297-326.

Krier, James E. and Stewart J. Schwab (1995), "Property Rules and Liability Rules: The Cathedral in another Light," The New York University Law Review, Vol. 70, 440-483.

Levmore, Saul (1997), "Unifying Remedies: Property Rights, Liability Rules, and Startling Rules,” Yale Law Journal, Vol. 106, 2149.

Macleod, W. B. and J. M. Malcomson (1993), "Investments, Holdup and the Form of Market Contracts," The American Economic Review, Vol. 83, 811-837.

Merrill, Thomas W. (1985), "Trespass, Nuisance, and the Costs of Determining Property Rights," The Journal of Legal Studies, Vol. 14, 13-48.

Noldeke, G. and K. Schmidt (1995), "Option Contracts and Renegotiation: A Solution to the Hold-Up Problem," The Rand Journal of Economics, Vol. 26, 163-179.

Pitchford, Rohan and Christopher Snyder (1999), "Incomplete Contracts and the Problem of Social Harm," mimeo, Australian National University and George Washington University.

Polinsky, A. Mitchell (1979), "Controlling Externalities and Protecting Entitlements: Property Rights, Liability Rules and Tax-Subsidy Approaches," The Journal of Legal Studies, Vol. 8, $1-48$.

Polinsky, A. Mitchell (1980a), "Resolving Nuisance Disputes: The Simple Economics of Injunctive and Damage Remedies,” The Stanford Law Review, Vol. 32, 1075-1113.

Polinsky, A. Mitchell (1980b), "On the Choice Between Property Rules and Liability Rules," Economic Inquiry, Vol. 18, 233-246.

Rajan, Raghuram G. and Luigi Zingales (1998), "Power in a Theory of the Firm," The Quarterly Journal of Economics, Vol. 113, 387-432.

Rogerson, W. P. (1984), "Efficient Reliance and Damage Measures for Breach of Contract," The Rand Journal of Economics, Vol. 15, 39-53.

Rogerson, W. P. (1992), "Contractual Solutions to the Hold-Up Problem," The Review of Economic Studies, Vol. 59, 777-794. 
Schankerman, Mark and Suzanne Scotchmer (2001), "Damages and Injunctions in Protecting Intellectual Property," Rand Journal of Economics, Vol. 32, 199-220.

Shavell, Steven (1980), "Damage Measures for Breach of Contract," The Bell Journal of Economics, Vol. 11, 466-490.

Shavell, Steven (1987), Economic Analysis of Accidents Law.

Symposium, Property Rules, Liability Rules, and Inalienability: A Twenty-Five Year Retrospective (1997), Yale Law Journal, Vol. 106, 2081-2213.

Williamson, Oliver E. (1975), Markets and Hierarchies: Analysis and Antitrust Implications, Free Press, New York.

Williamson, Oliver E. (1979), "Transaction-Cost Economics: The Governance of Contractual Relations," The Journal of Law and Economics, Vol. 22, 233-261. 